\title{
Patient Adherence to Olmesartan/Amlodipine Combinations: Fixed Versus Extemporaneous Combinations
}

\author{
Miriam Levi, MD; Alessandro Pasqua, MSc; lacopo Cricelli; Claudio Cricelli, MD; \\ Carlo Piccinni, PharmD, PhD; Damiano Parretti, MD; and Francesco Lapi, PharmD, PhD
}

\begin{abstract}
BACKGROUND: Lack of adherence to prescribed therapies is often a cause of suboptimal blood pressure control in patients with hypertension. To enhance patients' adherence to treatment, fixed-dose combinations of active substances with complementary mechanisms of action have been developed. An angiotensin-converting enzyme inhibitor or an angiotensin receptor blocker (ARB) is often combined with a calcium channel blocker. Olmesartan is the most used ARB in combination therapy. In Italy, in September 2011, a fixed-dose combination of olmesartan/amlodipine (olmesartan/amlodipine $20 / 5 \mathrm{mg}, 40 / 5 \mathrm{mg}$, or $40 / 10 \mathrm{mg}$ ) was introduced to treat patients with hypertension for whom control of blood pressure is not reached with either olmesartan or amlodipine alone. Prior research on adherence to olmesartan/amlodipine combinations was carried out in local contexts (e.g., claims databases of Italian regions or local health authorities), and/or it was limited by the fact that adherence was assessed against monotherapies already known for their low compliance profile, such as diuretics.
\end{abstract}

OBJECTIVE: To compare adherence with olmesartan/amlodipine fixed-dose combination (FDC) and extemporaneous combination in primary care in Italy. METHODS: A nationwide, population-based study was conducted by using the Health Search IMS Health Longitudinal Patient Database. Patients aged $>17$ years, affected by hypertension and treated with the FDC or extemporaneous combination of olmesartan/amlodipine, were identified. Adherence to these 2 therapeutic regimens was estimated by calculating the proportion of days covered (PDC). Patients were classified into 3 levels of adherence: high ( $P D C \geq 80 \%$ ), intermediate ( $P D C=40 \%-79 \%$ ), or low (PDC $<40 \%$ ).

RESULTS: In the 6-month follow-up, FDC showed higher adherence compared with an extemporaneous combination $(55.1 \%$ vs. $15.9 \%, P<0.001)$. This difference was confirmed in a multivariable logistic regression model clustered on patient identifier (odds ratio $=6.65 ; 95 \% \mathrm{Cl}=3.10-14.26$; $P<0.001$ ). The proportion of patients adherent to FDC varied from $60.4 \%$ for the $40 / 5 \mathrm{mg}$ formulation to $47.5 \%$ for the $40 / 10 \mathrm{mg}$ formulation.

CONCLUSIONS: These findings suggest that higher adherence may be achieved with FDCs than with extemporaneous combinations. To improve the degree of adherence, general practitioners may consider prescribing fixed combinations of antihypertensive agents as soon as monotherapies fail to achieve the expected therapeutic objective.

J Manag Care Spec Pharm. 2016;22(3):255-62

Copyright $\odot 2016$, Academy of Managed Care Pharmacy. All rights reserved.

\section{What is already known about this subject}

Fixed-dose combinations (FDCs) of medications with complementary mechanisms of action have been recently launched in Italy to better control blood pressure in hypertensive patients. Prior research on adherence to olmesartan/amlodipine combinations was restricted to local contexts (e.g., claims databases of Italian regions or local health authorities) or was limited by the fact that adherence was assessed against monotherapies already known for their low compliance rate, such as diuretics.

\section{What this study adds}

In terms of adherence, olmesartan/amlodipine FDC was compared with an extemporaneous-combination regimen of the same drug components (i.e., an appropriate comparator) in primary care in Italy.

During the 6-month follow-up, a greater proportion of patients were adherent to the FDC than to the extemporaneous combination.

H ypertension is a major public health concern. It is the leading cause of cardiovascular diseases, accounting for 9.4 million annual deaths globally and for the $7 \%$ of the total disability-adjusted life years in 2010., ${ }^{1,2}$ Despite the remarkable therapeutic advances and their protective effects on cardiovascular outcomes, pharmacological treatment is often suboptimal and the blood pressure control is inadequate in large proportions of patients. ${ }^{3,4}$ In the United States, according to the National Health and Nutrition Examination Survey 20112012, blood pressure control lower than 140/90 millimeters of mercury $(\mathrm{mm} \mathrm{Hg})$ was reached in only $51.8 \%$ of patients with documented hypertension. ${ }^{5}$ In Europe, blood pressure control is generally far from optimal. For example, $61.1 \%$ of patients presented good control of blood pressure in the primary care setting in Spain ${ }^{6}$; estimates for France show that only half of treated patients are under control ${ }^{7}$; in Italy, blood pressure was under control in $43.2 \%$ of the patients ${ }^{8}$; and approximately one third of patients under treatment reached targeted blood pressure goals in 9 central and eastern European countries. ${ }^{9}$

A lack of compliance with antihypertensive treatment is a very common phenomenon in primary care, ${ }^{10-12}$ which strongly influences blood pressure control, with a relevant impact on the cardiovascular risk and on the financial burden 
sustained by the National Health System. ${ }^{13-15}$ A meta-analysis demonstrated that there was a $20 \%$ reduction in the number of cardiovascular diseases for patients with high adherence versus patients with low adherence to antihypertensive medications. ${ }^{16}$ In 2003, the World Health Organization stated that improving adherence to antihypertensive therapy could be an important source of health, economic, and social advancement. ${ }^{17}$

There can be several reasons why patients discontinue drug treatment. Among nonclinical causes, poor socioeconomic status, illiteracy, and unemployment have been associated with lower adherence. ${ }^{18-20}$ The self-management of a complex drug therapy is the main cause of lack of adherence, especially among elderly patients with a high number of comorbidities and polypharmacy. Indeed, the safety profile and the number of concurrent medications play a significant role in patients' adherence. ${ }^{15,21}$ Furthermore, patients' adherence may be influenced by previous use of antihypertensive medications (i.e., being a prevalent rather than an incident user), and adherence changes after switching to other formulations are clinically relevant. ${ }^{22,23}$

In this context, several studies showed that persistence with antihypertensive drugs is lower in patients treated with diuretics and/or beta-blockers and higher in those treated with inhibitors of the renin-angiotensin-aldosterone system. ${ }^{12,24,25}$ Recent evidence shows that adherence to medications is inversely related to the number of antihypertensive drugs being administered. ${ }^{26,27}$ One of the measures introduced to enhance patients' adherence to antihypertensive drugs and to maximize the benefits of these therapies was the development of fixeddose combinations (FDCs) of medications with complementary mechanisms of action. A combination therapy is recommended as first-line treatment in patients at high or very high cardiovascular risk or for whom blood pressure is markedly above the hypertension threshold (i.e., > $20 \mathrm{~mm} \mathrm{Hg}$ systolic or $10 \mathrm{~mm} \mathrm{Hg}$ diastolic). ${ }^{13,28,29}$ However, in the most recent guidelines issued by the European Society of Hypertension and the European Society of Cardiology, the use of an FDC is a class IIb recommendation, meaning that the usefulness/efficacy has not been yet well established by evidence/opinion. ${ }^{29}$ Additionally, it has been demonstrated that an earlier blood pressure target is more easily achieved using a low-dose combination therapy compared with full-dose monotherapy. This therapeutic approach has a better tolerability profile because lower doses of the drugs are used. ${ }^{30,31}$ It was also demonstrated that adherence is favorably influenced by starting treatment as soon as possible with an FDC, because FDCs are characterized by lower drop-out rates than monotherapies. ${ }^{32,33}$

Nowadays, FDCs are widely available. An angiotensin-converting enzyme inhibitor or an angiotensin receptor blocker is often combined with a calcium channel blocker. Olmesartan is the most commonly used angiotensin receptor blocker in com- bination therapy because of its high antihypertensive efficacy and favorable safety profile. In Italy, in September 2011, an FDC of olmesartan/amlodipine (olmesartan/amlodipine 20/5 $\mathrm{mg}, 40 / 5 \mathrm{mg}$, or $40 / 10 \mathrm{mg}$ ) was introduced to treat patients with hypertension for whom blood pressure control is not reached with either olmesartan or amlodipine alone. Prior research on adherence to olmesartan/amlodipine combinations was conducted in a local context ${ }^{34,35}$ or was limited by the fact that adherence was assessed against monotherapies already known for their low compliance profile, such as diurectics. ${ }^{33}$ Given the uncertainty surrounding the usefulness of an FDC for increasing patients' adherence to treatment, we carried out the present study to compare adherence to olmesartan/amlodipine FDC with adherence to extemporaneous combinations in primary care in Italy, using data from the population-based, prospective Health Search IMS Health Longitudinal Patient Database (HS IMS Health LPD), thus evaluating the usefulness of this FDC in real-world practice.

\section{Methods}

\section{Data Source}

Information was obtained from the HS IMS Health LPD, an Italian general practice database in place since 1998 (data have been recorded since 1996) comprising data from computerbased patient records registered by a selected group of general practitioners (GPs), uniformly distributed throughout the whole national territory. GPs voluntarily agreed to contribute to the general practice database and to attend specific training courses for data entry. Patient demographic details included in HS IMS Health LPD are linked through the use of an encrypted patient code with medical records (diagnoses, tests, tests results, procedures, hospital admissions), information on drug prescriptions, lifestyle information (alcohol, body mass index, smoking habit), and date of death. Diseases were classified according to the International Classification of Diseases, Ninth Revision, Clinical Modification (ICD-9-CM). The encoding of the ambulatory procedures is done in accordance with the Nomenclatore Tariffario, a list of all outpatient specialist medical services and related tariffs instituted by Ministerial Decree in 1996.36

To be considered for participation in epidemiological studies, GPs must meet up-to-standard quality criteria pertaining to the levels of coding, prevalence of well-known diseases, mortality rates, and years of recording. ${ }^{37}$ Quality and consistency of data collected in the database were well demonstrated through several studies in which the retrieved information was compared with other current data sources or findings from national surveys. ${ }^{38-40}$

At the beginning of the present study, 700 GPs homogeneously distributed across Italy, covering a patient population of $1,222,595$, reached the up-to-standard quality 
criteria. The study was based on the records collected by these GPs. Specifically, for each prescribed drug, the following information was registered: trade name, dosage form, Anatomical Therapeutic Chemical (ATC) code, ministerial code and active substance, date of filled prescription, and days of supply.

\section{Study Cohorts}

All patients aged $>17$ years who were diagnosed with hypertension (ICD-9-CM codes 401* through 404* and 437.2) and who were treated either with the olmesartan/amlodipine extemporaneous combination (ATC codes C08CA01 and C09CA08) or with the olmesartan/amlodipine FDC (ATC code C09DB02; formulations used: 20/5 mg, 40/5 mg, and 40/10 mg) were identified. For the extemporaneous-combination users, an overlapping prescription was operationally defined as a prescription for 1 of the 2 components before or on the run-out date (prescription date plus days of supply) of the other component. Only periods of overlapping prescriptions were considered for extemporaneous-combination users. The observation period started when the 2 different formulations under investigation were made available in the market: January, 1, 2005, when olmesartan became available in Italy, for patients treated with the extemporaneous combination; and September, 1, 2011, for patients treated with the FDC. For each patient, the first occurrence of a prescription of the extemporaneous combination or the FDC during the respective observation periods was the index date. Among extemporaneous-combination users, the index date therefore coincided with the first prescription date for the second component when overlapping the first component. To be considered eligible, patients were required to have at least 2 years of medical history in HS IMS Health LPD and at least 6 months of follow-up. Patients were followed from the index date until the end of registration with the GP, the end of the study period (i.e., December, 31, 2010, for patients prescribed the extemporaneous combination and December, 31, 2012, for patients prescribed the FDC), the last day of the sixth month of follow-up, or death, whichever occurred first.

\section{Assessment of Adherence}

Adherence to antihypertensive therapy was defined as the extent to which patients followed their antihypertensive medication schedules as prescribed by their GPs. ${ }^{41}$ It was estimated by calculating the proportion of days covered (PDC), which is the proportion of days on which a patient had pills available during follow-up. The PDC corresponded to the total days of supply of medication dispensed divided by the length of the corresponding follow-up and multiplied by 100. The number of days supplied by each prescription was calculated by dividing the total amount of active drug in each prescription by the recommended defined daily dose. Patients were therefore classified into 3 adherence levels: high (PDC $\geq 80 \%$ ), intermediate (PDC $=40 \%-79 \%$ ), or low ( $\mathrm{PDC}<40 \%$ ), as currently categorized in the literature. ${ }^{42}$ We compared the level of adherence between the olmesartan/amlodipine FDC and the extemporaneous combination by calculating PDC for both the FDC and the extemporaneous-combination cohorts over a 6-month follow-up period.

\section{Covariates}

We identified all variables considered as potential risk factors for different degrees of adherence to antihypertensive drugs, as well as variables that could be potential confounders of the degree of adherence to the formulation (FDC vs. extemporaneous combination). The following covariates were assessed for both FDC and extemporaneous-combination users: sex and age on the index date; family history of cardiovascular disease; obesity; comorbidities (diabetes mellitus or metabolic syndrome, cardiac arrhythmias, peripheral vascular disease, chronic kidney disease, adrenal glands disorders, dyslipidemia, coronary artery diseases, cerebrovascular disorders, congestive heart failure, thyroid diseases, gout/hyperuricemia) before and/or on the index date; laboratory test results registered in the 12 months before and/or on the index date (blood pressure, total cholesterol, low-density lipoprotein cholesterol, highdensity lipoprotein cholesterol, hemoglobin Alc); number of hospital admissions; number of specialist visits; and concomitant medications prescribed during the 6 months before and/ or on the index date (antihyperglycemic drugs [ATC code A10], antithrombotics [ATC code B01A], cardiac therapy [ATC code C01A], antiarrhythmics [ATC code C01B], corticosteroids [ATC code H02], nonsteroidal anti-inflammatory drugs [ATC code M01A], antidepressants [ATC code N06A], thyroid therapy [ATC code H03], oral contraceptives [ATC code G03A], lipidlowering agents [ATC code C10], and number of concomitant drugs [i.e., ATC codes]).

\section{Statistical Analysis}

A descriptive statistical analysis for categorical variables (absolute frequency, relative frequency, 95\% confidence intervals [CIs]) and continuous variables (mean, median, standard deviation [SD]) was carried out. We used univariable logistic and linear regression to compare characteristics of FDC and extemporaneous-combination users for categorical and continuous variables, respectively. Given that the observations were not fully independent (i.e., some FDC users could be selected in both cohorts because they were previously exposed to other antihypertensive drugs, including the extemporaneous combination), each regression model was corrected for clustering on patient identifier. ${ }^{43}$ 
TABLE 1 Demographic and Clinical Characteristics of Patients Treated with Olmesartan/Amlodipine Fixed-Dose and Extemporaneous Combinations ${ }^{a}$

\begin{tabular}{|c|c|c|c|c|c|c|}
\hline Patient Characteristics & $\begin{array}{c}\text { FDC } \\
\text { Overall } \\
(\mathrm{N}=4,522) \\
\end{array}$ & $\begin{array}{c}20 / 5 \mathrm{mg} \text { FDC } \\
\text { Formulation } \\
(\mathrm{n}=2,660)\end{array}$ & $\begin{array}{c}40 / 10 \mathrm{mg} \text { FDC } \\
\text { Formulation } \\
(\mathrm{n}=942)\end{array}$ & $\begin{array}{c}40 / 5 \mathrm{mg} \text { FDC } \\
\text { Formulation } \\
(\mathrm{n}=920)\end{array}$ & $\begin{array}{c}\text { Extemporaneous } \\
\text { Combination } \\
(\mathrm{N}=2,090)\end{array}$ & $P$ Value $^{\mathrm{b}}$ \\
\hline \multicolumn{7}{|l|}{ Demographics } \\
\hline Mean (SD) age, years & $66.6(12.6)$ & $66.4(12.9)$ & $66.8(12.4)$ & $67 \quad(12.0)$ & $68.1 \quad(11.6)$ & 0.002 \\
\hline Female, \% & 52.2 & 53.9 & 46.3 & 53.5 & 50.8 & 0.267 \\
\hline \multicolumn{7}{|l|}{ Medical history/medical examination, \% } \\
\hline Family history of $\mathrm{CV}$ diseases ${ }^{c}$ & 19.2 & 20.2 & 16.7 & 18.9 & 17.4 & 0.077 \\
\hline Obesity & 26.8 & 23.3 & 33.4 & 29.9 & 28.5 & 0.130 \\
\hline \multicolumn{7}{|l|}{ Comorbidities, $\%^{c}$} \\
\hline Diabetes mellitus & 29.2 & 25.8 & 39.2 & 28.6 & 30.3 & 0.326 \\
\hline Arrhythmias & 12.8 & 12.7 & 11.7 & 13.9 & 13.7 & 0.294 \\
\hline Peripheral vascular diseases & 15.0 & 13.3 & 19.1 & 16.0 & 14.1 & 0.317 \\
\hline Chronic kidney disease & 8.6 & 7.3 & 10.8 & 10.0 & 9.9 & 0.091 \\
\hline Adrenal gland disorders & 0.3 & 0.3 & 0.3 & 0.5 & 0.6 & 0.084 \\
\hline Dyslipidemia & 32.5 & 30.4 & 34.8 & 36.3 & 32.7 & 0.888 \\
\hline Coronary artery disease & 13.5 & 12.1 & 15.8 & 14.9 & 18.1 & $<0.001$ \\
\hline Cerebrovascular diseases & 13.9 & 13.0 & 16.2 & 14.0 & 16.6 & 0.004 \\
\hline Congestive heart failure & 2.6 & 2.5 & 2.4 & 3.2 & 4.2 & 0.001 \\
\hline Thyroid diseases & 20.8 & 20.0 & 20.7 & 23.0 & 18 & 0.008 \\
\hline Gout/hyperuricemia & 10.8 & 9.4 & 14.1 & 11.7 & 10.5 & 0.700 \\
\hline \multicolumn{7}{|l|}{ Test results ${ }^{\mathrm{d}}$} \\
\hline Mean (SD) systolic BP, mm Hg & $148.3(18.5)$ & $146.9 \quad(17.2)$ & $152 \quad(20.5)$ & $148.4 \quad(19.2)$ & $144.7 \quad(17.3)$ & 0.002 \\
\hline Mean (SD) diastolic BP, mm Hg & $85.2(11.0)$ & $84.9(10.5)$ & $85.7(10.8)$ & $85.6(12.4)$ & $83.6(12.9)$ & 0.080 \\
\hline Mean (SD) total cholesterol, $\mathrm{mg} / \mathrm{dL}$ & $202.4 \quad(42.2)$ & $203.8 \quad(41.6)$ & $196.4 \quad(41.8)$ & $205 \quad(43.8)$ & $203.1(38.8)$ & 0.031 \\
\hline Mean (SD) LDL cholesterol, mg/dL & $121.8 \quad(45.0)$ & $123.3(50.2)$ & $116.7 \quad(37.5)$ & $122.7(36.4)$ & $122.4(34.6)$ & 0.129 \\
\hline Mean (SD) HDL cholesterol, mg/dL & $52.5(15.7)$ & $53.3(16.6)$ & $50.8 \quad(14.6)$ & $52.4(13.9)$ & $52.1 \quad(14.3)$ & 0.471 \\
\hline Mean (SD) HblAc, \% & $7.8 \quad(6.4)$ & $7.6 \quad(6.2)$ & $7.8 \quad(4.9)$ & $8.1 \quad(8.4)$ & $7 \quad(1.3)$ & $<0.001$ \\
\hline Mean (SD) number of hospitalizations & $1.1 \quad(0.3)$ & $1.1 \quad(0.3)$ & $1.1 \quad(0.4)$ & $1.1 \quad(0.4)$ & $0.2 \quad(0.6)$ & $<0.001$ \\
\hline Mean (SD) number of visits to a specialist & $2.7 \quad(1.9)$ & $2.7 \quad(2.0)$ & $2.7 \quad(1.9)$ & $(1.8)$ & $(2.9)$ & 0.002 \\
\hline \multicolumn{7}{|l|}{ Concomitant therapies, \%e } \\
\hline Antihyperglycemic drugs & 22.8 & 19.8 & 31.8 & 22.2 & 24 & 0.268 \\
\hline Antithrombotics & 41.2 & 38.0 & 47.8 & 43.6 & 49.3 & $<0.001$ \\
\hline Cardiac drug therapy & 1.4 & 1.1 & 1.6 & 2.0 & 4.6 & $<0.001$ \\
\hline Antiarrhythmics & 3.6 & 3.6 & 3.5 & 3.7 & 5.8 & $<0.001$ \\
\hline Corticosteroids & 9.6 & 9.7 & 8.9 & 10.0 & 14 & $<0.001$ \\
\hline NSAIDs & 33.3 & 34.5 & 31.8 & 31.4 & 45.4 & $<0.001$ \\
\hline Antidepressant drugs & 10.3 & 10.0 & 11.4 & 10.2 & 14.7 & $<0.001$ \\
\hline Thyroid therapy & 8.2 & 8.4 & 7.1 & 8.6 & 7.6 & 0.415 \\
\hline Oral contraceptives & 0.3 & 0.4 & 0.1 & 0.3 & 0.7 & 0.058 \\
\hline Lipid-modifying agents & 35.2 & 32.8 & 39.3 & 37.9 & 37.5 & 0.063 \\
\hline Mean (SD) number of medications & $8.3 \quad(4.7)$ & $7.9 \quad(4.6)$ & $9.3 \quad(5.0)$ & $8.4 \quad(4.4)$ & \begin{tabular}{|l|}
$2.6 \quad(1.8)$ \\
\end{tabular} & $<0.001$ \\
\hline \multicolumn{7}{|c|}{$\begin{array}{l}\text { aPatients prescribed the fixed-dose combination were further stratified by the formulations used (20/5 mg, } 40 / 10 \mathrm{mg} \text {, or } 40 / 5 \mathrm{mg}) \text {. } \\
\text { bP values refer to comparisons between FDC and extemporaneous-combination users. } \\
\text { cIn the period prior to the index date (data have been recorded since 1996). } \\
\text { dRegistered in the } 12 \text { months before and/or on the index date. } \\
\text { ePrescribed during the } 6 \text { months before and/or on the index date. } \\
\text { BP=blood pressure; } C V=\text { cardiovascular; FDC = fixed-dose combination; HblAc=hemoglobin Alc; HDL=high-density lipoprotein; LDL=low-density lipoprotein; } \\
m m \text { Hg = millimeters of mercury; NSAID=nonsteroidal anti-inflammatory drug; SD=standard deviation. }\end{array}$} \\
\hline
\end{tabular}

A multivariable logistic regression model adjusted for all the aforementioned covariates was also used to compare adherence rates among FDC patients versus extemporaneous-combination patients. In line with univariate analysis, the multivariable model was still clustered on patient identifier because the exposure categories were not fully independent. Statistical significance was defined as a 2 -tailed value of $P<0.05$. Estimates of adherence levels with 95\% CIs and probability values were generated with STATA software, version 11 (STATACorp, College Station, TX). 
FIGURE 1 Comparison of Adherence to Olmesartan/Amlodipine Fixed-Dose Combination with Adherence to the Extemporaneous Combination in Incident Users at 6-Month Follow-up

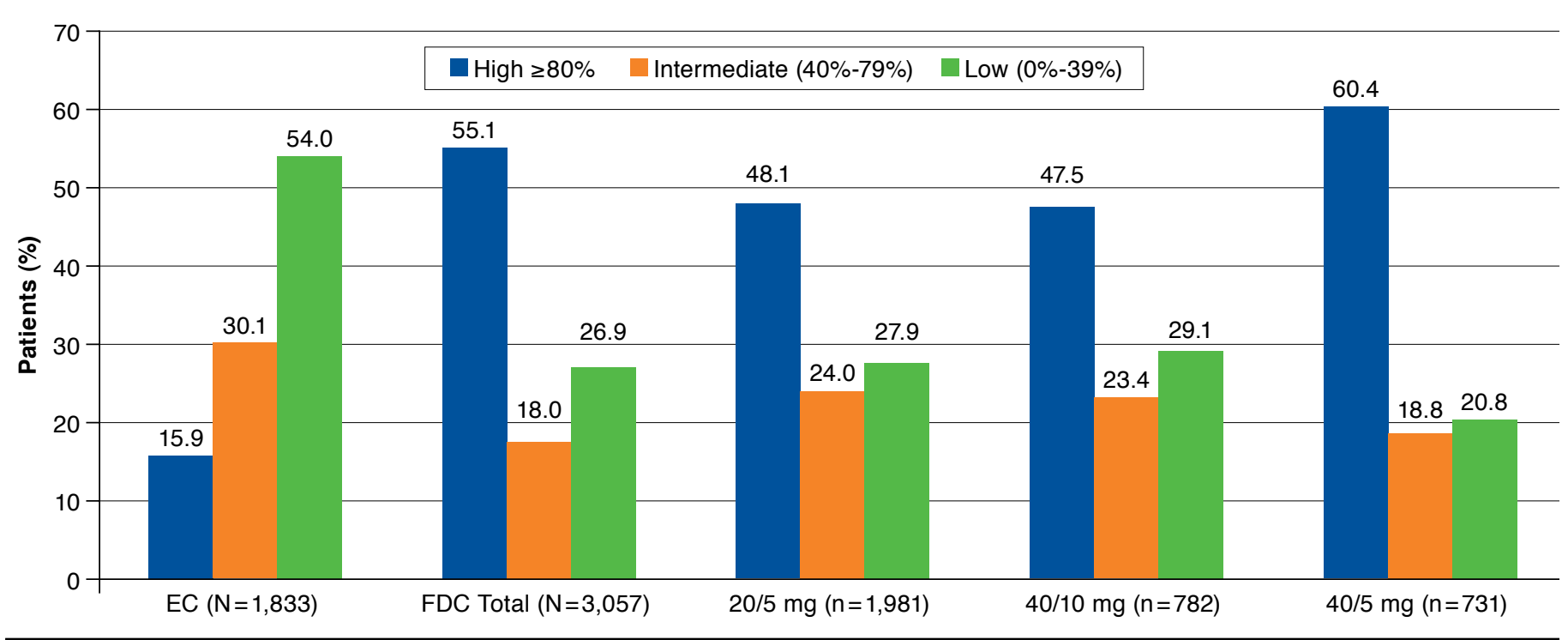

EC=extemporaneous combination; FDC = fixed-dose combination

\section{Results}

Demographic and Clinical Characteristics of OImesartan/ Amlodipine FDC and Extemporaneous-Combination Users

Table 1 depicts the demographic and clinical characteristics of patients exposed to the FDC or the extemporaneous combination. Out of a population of about $1,222,595$ individuals, 2,090 patients had at least 1 prescription for the extemporaneous combination of olmesartan/amlodipine filled from January, 1, 2005, to December, 31, 2010. The mean \pm SD age of the patients was $68.1 \pm 11.6$ years and $50.8 \%$ were women. Between September 2011 and December 2012, a total of 4,522/1,222,595 patients were exposed to the olmesar$\tan /$ amlodipine FDC. The mean \pm SD age of the patients was $66.6 \pm 12.6$ years and $52.2 \%$ were women. In most cases the 2 cohorts were similar, but patients treated with the extemporaneous combination showed a higher prevalence of coronary heart disease and cerebrovascular events compared with patients treated with the FDC $(18.1 \%$ vs. $13.5 \%[P<0.001]$ and $16.6 \%$ vs. $13.9 \%[P=0.004]$, respectively). In contrast, systolic blood pressure levels were significantly higher among patients treated with the FDC versus those treated with the extemporaneous combination (mean systolic arterial pressure: $148.3 \mathrm{~mm}$ $\mathrm{Hg}$ vs. $144.7 \mathrm{~mm} \mathrm{Hg}$; $=0.002$ ); this was also the case for the number of concomitant medications (8.3 vs. 2.6; $P<0.001)$.

With regard to the FDC, the clinical severity was higher in patients exposed to the $40 / 10 \mathrm{mg}$ formulation than in those treated with lower dosages. The prevalence of the following conditions was higher in patients on the higher dose: diabetes mellitus (39.2\%), obesity (33.4\%), peripheral vascular disease (19.1\%), cerebrovascular disease (16.2\%), coronary artery disease (15.8\%), and chronic kidney disease (10.8\%). The blood pressure levels were also higher, in particular the systolic blood pressure (mean \pm SD of $152.0 \pm 20.5 \mathrm{~mm} \mathrm{Hg}$ ), but also the diastolic blood pressure (mean \pm SD of $85.7 \pm 10.8 \mathrm{~mm} \mathrm{Hg}$; Table 1). A longer period of time (111.4 months) between diagnosis and the first FDC claim was registered with the 40/10 mg formulation compared with the other 2 formulations (108.7 months with 40/5 mg and 94.8 months with 20/5 $\mathrm{mg}$ ). In more than $65 \%$ of cases, patients newly treated with the FDC were previously treated with monotherapy, 24\% were previously treated with combination therapy, and $8.3 \%$ were not previously treated. Of note, only $0.3 \%$ of patients were previously prescribed the olmesartan/amlodipine extemporaneous combination.

\section{Adherence}

At 6 months from the index date, more than half of patients newly treated with the olmesartan/amlodipine FDC (55.1\%) were found to be highly adherent (PDC $>80 \%$ ) to therapy, whereas among patients treated with the olmesartan/amlodipine extemporaneous combination, $15.9 \%$ had a PDC $>80 \%$ $(P<0.001$; Figure 1). This difference was confirmed after adjusting for the covariates in the multivariable logistic regression model clustered on patient identifier (odds ratio $=6.65$; 95\% CI =3.10-14.26; $P<0.001)$.

As for the FDC, the proportion of highly adherent patients varied from $47.5 \%$ for the $40 / 10 \mathrm{mg}$ formulation to $60.4 \%$ for the 
$40 / 5 \mathrm{mg}$ formulation. The proportion of patients with intermediate adherence ranged from $18.8 \%$ (40/5 mg) to $24 \%$ (20/5 mg). The mean \pm SD PDC was $41.4 \pm 30.5$ for extemporaneous-combination users; $75.6 \pm 32.0$ for FDC users (in total); $71.0 \pm 34.2$ for 20/5 mg FDC users; $67.8 \pm 33.5$ for 40/10 mg FDC users; and $67.2 \pm 33.9$ for $40 / 5 \mathrm{mg}$ FDC users.

\section{Discussion}

To our knowledge, this large study, conducted on a sample representative of the general adult Italian population, is the first to compare adherence to olmesartan/amlodipine FDC with adherence to the extemporaneous combination in a real-world setting, taking into account many demographic, clinical, and lifestyle variables.

Prior studies have already shown that incident users of antihypertensive FDC medications have greater adherence than those using extemporaneous combinations. However, they had a number of shortcomings and/or left several aspects of this topic understudied. In a previous study based on data obtained from the HS IMS Health LPD, improved adherence (29\%) was associated with combination therapies compared with single therapies,,$^{15}$ but FDCs were not specifically evaluated separately from extemporaneous combinations. Indeed, this study was carried out prior to the availability in the market of the olmesartan/amlodipine FDC. In a prospective observational study carried out in Spain, loose-pill combination antihypertensive therapy was associated with lower odds of being adherent compared with FDC antihypertensive therapy. ${ }^{35}$ Also in this case, because the study was conducted between 2007 and 2009, adherence to the olmesartan/amlodipine FDC could not be assessed. In another study, ${ }^{33}$ conducted using claim databases, the use of an FDC or extemporaneous combination as first-choice treatment was associated with a reduced risk of treatment discontinuation compared with diuretic monotherapy. However, diuretics have a low level of compliance because of their frequent adverse events; therefore, the use of this treatment regimen as a comparator to assess the advantages offered by the FDCs might be inadequate. In a recent retrospective cohort study by Degli Esposti et al. (2014), ${ }^{34}$ including 21,008 patients previously treated with the olmesartan/amlodipine extemporaneous combination, the number of adherent patients increased by $24 \%$ after they switched to the FDC. However, such results cannot be applied to the entire Italian population because the study population only refers to 3 local health authorities. Finally, in a European multicenter, prospective, noninterventional study, adherence to the FDC of olmesartan/amlodipine/hydrochlorothiazide was measured using the Morisky Medication Adherence Scale, a nonstandardized questionnaire for patients for self-assessment. ${ }^{44}$ Although self-administered surveys might be affected by information bias, ${ }^{45,46}$ the results of this study were consistent with ours as well as with those obtained in clinical trials, ${ }^{47,48}$ showing that FDCs are able to improve medication adherence.
With our study, we also attempted to overcome the weaknesses of prior works. First, findings from the present study stem from data covering a patient population of more than 1,200,000 individuals, representative of the entire Italian population. Second, the olmesartan/amlodipine FDC was compared in terms of adherence with a loose-dose combination regimen of the same drug components, i.e., with an appropriate comparator. Third, adherence was assessed using PDCs resulting from GPs' prescriptions, thus reducing the risk of information bias.

The use of the FDC greatly improved medication adherence compared with the 2-pill combination ( $55.1 \%$ vs. $15.9 \%$ ). The difference observed was confirmed after adjusting for the covariates in a multivariable logistic regression model; the proportion of adherent patients varied according to the formulation used.

\section{Limitations}

This study has some limitations. First, although this study was conducted using detailed patient and prescription data, patient exposure to the drugs was obtained from the prescription records of GPs, so it is possible that the true adherence to the therapeutic regimens was overestimated. However, to assess adherence to medications, direct measures (e.g., directly observing therapy intake) or measuring drug/metabolite blood levels in patients are expensive, impractical, and often inaccurate for routine use..$^{49}$ Moreover, rates and volumes (i.e., defined daily doses) of prescriptions by GPs, such as those obtained from the HS IMS Health LPD for the purpose of the present study, have been shown to be consistent with those measured by data sources providing information on dispensed medications ${ }^{40}$ along with accurate measures of overall compliance. ${ }^{50-52}$ On the other hand, information on drug prescriptions would have been missed wherever patients received prescriptions by physicians working in the private sector. Nonetheless, it must be noted that antihypertensive drugs are completely reimbursed by the National Healthcare System if prescribed by GPs. Therefore, our estimates may be considered fairly accurate.

Second, because the allocation of patients into the FDC or extemporaneous-combination cohorts was not randomized, an imbalance in the underlying variables generally associated with adherence to medications (e.g., comorbidities) may have occurred and comparison among the 2 treatment groups may have generated biased results. However, we adjusted the regression model for several covariates, and it is hard to imagine that the magnitude observed for the results concerning adherence to the FDC versus the extemporaneous combination is completely because of unmeasured confounders.

Finally, data were recorded in the database as soon as they became available, which is September 2011 for the FDC. Therefore, for the purpose of the present study, a 6-month period was available for comparing adherence levels with the extemporaneous combination versus the FDC. A longer time 
frame may have captured more clinically relevant variations in adherence behaviors.

\section{Conclusions}

Among the recommendations developed by the World Health Organization for improving adherence, the following is included: "Health care providers should also be trained to make a rational selection of antihypertensive drugs. The drug selected should be available, affordable, have a simple dosing regimen, and ideally, should not interfere with the quality of life of the patient." ${ }^{\prime 7}$ The development of FDCs was prompted by the evidence that the simpler the therapeutic regimen, the better the patient's adherence and the outcomes of diseases. Our findings confirmed that the use of olmesartan/amlodipine FDC in a primary care setting is associated with greater adherence compared with the 2-pill combination. To improve the degree of adherence, GPs may consider prescribing fixed combinations of antihypertensive agents as soon as monotherapies fail to achieve the expected therapeutic results.

\section{Authors}

MIRIAM LEVI, MD, is Research Fellow, Department of Health Sciences, University of Florence, Florence, Italy. ALESSANDRO PASQUA, MSc, is Chief Statistician; IACOPO CRICELLI, is General Director; and FRANCESCO LAPI, PharmD, PhD, is Research Director, Health Search, Italian College of General Practitioners and Primary Care, Florence, Italy. CLAUDIO CRICELLI, MD, is President, and DAMIANO PARRETTI, MD, is General Practitioner, Italian College of General Practitioners and Primary Care, Florence, Italy. CARLO PICCINNI, PharmD, PhD, is Postdoctoral Researcher, Department of Medical and Surgical Sciences-Pharmacology Unit, University of Bologna, Bologna, Italy.

AUTHOR CORRESPONDENCE: Miriam Levi, MD, Department of Health Sciences, University of Florence, Viale G. B. Morgagni, 48, 50134 Florence, Italy. Tel.: +39 055 2751082;

Fax: +39 055 2751093; E-mail: miriam.levi@unifi.it.

\section{DISCLOSURES}

This study was funded by Menarini Farmaceutici Riuniti. The funding institution had no role in the design, analysis, and interpretation of the results. Lapi and Cricelli provided consultancies in protocol preparation for epidemiological studies and data analyses for IBSA and Bayer. Cricelli and Parretti provided clinical consultancies for IBSA, Bayer, and Alfa Wasserman. Levi, Pasqua, and Piccinni have no conflicts of interest to disclose.

Study design was contributed by C. Cricelli and Lapi, with assistance from the rest of the authors. Pasqua and I. Cricelli took the lead in data collection, assisted by the other authors, and data interpretation was performed by Levi, Piccinni, and Lapi, with assistance from the other authors. The manuscript was written primarily by Levi and Paretti, with assistance from the other authors, and revised by I. Cricelli, C. Cricelli, and Lapi, assisted by the other authors.

\section{REFERENCES}

1. Lim SS, Vos T, Flaxman AD, et al. A comparative risk assessment of burden of disease and injury attributable to 67 risk factors and risk factor clusters in 21 regions, 1990-2010: a systematic analysis for the Global Burden of Disease Study 2010. Lancet. 2012;380(9859):2224-60.

2. Childress B. Innovations: IHME's recently published work. IHME Impact Issue 7. April 2013. Available at http://www.healthdata.org/newsletters/ impact-7/innovations. Accessed December 18, 2015.

3. Hajjar I, Kotchen JM, Kotchen TA. Hypertension: trends in prevalence, incidence, and control. Annu Rev Public Health. 2006;27:465-90.

4. Chobanian AV. Shattuck Lecture. The hypertension paradoxmore uncontrolled disease despite improved therapy. N Engl J Med. 2009;361(9):878-87.

5. Nwankwo T, Yoon SS, Burt V, Gu Q. Hypertension among adults in the United States: National Health and Nutrition Examination Survey, 20112012. NCHS Data Brief. 2013;(133):1-8.

6. Llisterri Caro JL, Rodríguez Roca GC, Alonso Moreno FJ, et al; en representación del Grupo de Trabajo de Hipertensión Arterial de la Sociedad Española de Atención Primaria (Grupo HTA/SEMERGEN) y de los investigadores del Estudio PRESCAP 2010. Blood pressure control in hypertensive Spanish population attended in primary care setting. The PRESCAP 2010 study [article in Spanish]. Med Clin (Barc). 2012;139(15):653-61.

7. Blacher J, Halimi J-M, Hanon O, et al; Société française d'hypertension artérielle. Management of arterial hypertension in adults: 2013 guidelines of the French Society of Arterial Hypertension [article in French]. Ann Cardiol Angeiol (Paris). 2013;62(3):132-38.

8. Filippi A, Paolini I, Innocenti F, Mazzaglia G, Battaggia A, Brignoli O. Blood pressure control and drug therapy in patients with diagnosed hypertension: a survey in Italian general practice. J Hum Hypertens. 2009;23(11):758-63.

9. Grassi G, Cifkova R, Laurent S, et al. Blood pressure control and cardiovascular risk profile in hypertensive patients from central and eastern European countries: results of the BP-CARE study. Eur Heart J. 2011;32(2):218-25.

10. Corrao G, Zambon A, Parodi A, et al. Discontinuation of and changes in drug therapy for hypertension among newly-treated patients: a populationbased study in Italy. J Hypertens. 2008;26(4):819-24.

11. Burke TA, Sturkenboom MC, Lu S, Wentworth CE, Lin Y, Rhoads GG. Discontinuation of antihypertensive drugs among newly diagnosed hypertensive patients in UK general practice. J Hypertens. 2006;24(6):1193-200.

12. Mazzaglia G, Mantovani LG, Sturkenboom MCJM, et al. Patterns of persistence with antihypertensive medications in newly diagnosed hypertensive patients in Italy: a retrospective cohort study in primary care. J Hypertens. 2005;23(11):2093-100.

13. Mancia G, Laurent S, Agabiti-Rosei E, et al. Reappraisal of European guidelines on hypertension management: a European Society of Hypertension Task Force document. Blood Press. 2009;18(6):308-47.

14. Sokol MC, McGuigan KA, Verbrugge RR, Epstein RS. Impact of medication adherence on hospitalization risk and healthcare cost. Med Care. 2005;43(6):521-30.

15. Mazzaglia G, Ambrosioni E, Alacqua M, et al. Adherence to antihypertensive medications and cardiovascular morbidity among newly diagnosed hypertensive patients. Circulation. 2009;120(16):1598-605.

16. Chowdhury R, Khan H, Heydon E, et al. Adherence to cardiovascular therapy: a meta-analysis of prevalence and clinical consequences. Eur Heart J. 2013;34(38):2940-48

17. World Health Organization. Adherence to Long-Term Therapies: Evidence for Action. Geneva, Switzerland: World Health Organization; 2003. Available at: http://whqlibdoc.who.int/publications/2003/9241545992.pdf. Accessed December 1, 2015. 
18. Bone LR, Hill MN, Stallings R, et al. Community health survey in an urban African-American neighborhood: distribution and correlates of elevated blood pressure. Ethn Dis. 2000;10(1):87-95.

19. Saounatsou M, Patsi O, Fasoi G, et al. The influence of the hypertensive patient's education in compliance with their medication. Public Health Nurs. 2001;18(6):436-42.

20. Zullig LL, Stechuchak KM, Goldstein KM, et al. Patient-reported medication adherence barriers among patients with cardiovascular risk factors. J Manag Care Spec Pharm. 2015;21(6):479-85. Available at: http://www.amcp. org/WorkArea/DownloadAsset.aspx?id=19646.

21. Düsing R. Adverse events, compliance, and changes in therapy. Curr Hypertens Rep. 2001;3(6):488-92.

22. Benner JS, Chapman RH, Petrilla AA, Tang SS, Rosenberg N, Schwartz JS. Association between prescription burden and medication adherence in patients initiating antihypertensive and lipid-lowering therapy. Am J Health Syst Pharm. 2009;66(16):1471-77.

23. Alghurair SA, Hughes CA, Simpson SH, Guirguis LM. A systematic review of patient self-reported barriers of adherence to antihypertensive medications using the World Health Organization multidimensional adherence model. J Clin Hypertens. 2012;14(12):877-86.

24. Erkens JA, Panneman MMJ, Klungel OH, van den Boom G, Prescott MF, Herings RM. Differences in antihypertensive drug persistence associated with drug class and gender: a PHARMO study. Pharmacoepidemiol Drug Saf. 2005;14(11):795-803.

25. Veronesi M, Cicero AF, Prandin MG, et al. A prospective evaluation of persistence on antihypertensive treatment with different antihypertensive drugs in clinical practice. Vasc Health Risk Manag. 2007;3(6):999-1005. Available at: https://www.dovepress.com/articles.php?article_id=1565. Accessed December 1, 2015

26. Claxton AJ, Cramer J, Pierce C. A systematic review of the associations between dose regimens and medication compliance. Clin Ther. 2001;23(8):1296-310

27. Chrysant SG. Triple-drug, fixed-dose combinations for the treatment of hypertension: focus on olmesartan/amlodipine/hydrochlorothiazide combination. Drugs Today (Barc). 2011;47(3):197-206.

28. Mancia G, De Backer G, Dominiczak A, et al. 2007 Guidelines for the management of arterial hypertension: the Task Force for the Management of Arterial Hypertension of the European Society of Hypertension (ESH) and of the European Society of Cardiology (ESC). Eur Heart J. 2007;28(12):1462-536.

29. Mancia G, Fagard R, Narkiewicz K, et al. 2013 ESH/ESC Guidelines for the management of arterial hypertension: the Task Force for the Management of Arterial Hypertension of the European Society of Hypertension (ESH) and of the European Society of Cardiology (ESC). J Hypertens. 2013;31(7):1281-357.

30. Pimenta E, Oparil S. Fixed combinations in the management of hypertension: patient perspectives and rationale for development and utility of the olmesartan-amlodipine combination. Vasc Health Risk Manag. 2008;4(3):65364. Available at: https://www.dovepress.com/articles.php?article_id=1910. Accessed December 1, 2015.

31. Kreutz R. Olmesartan/amlodipine: a review of its use in the management of hypertension. Vasc Health Risk Manag. 2011;7:183-92.

32. Chrysant SG. Using fixed-dose combination therapies to achieve blood pressure goals. Clin Drug Investig. 2008;28(11):713-34.

33. Corrao G, Parodi A, Zambon A, et al. Reduced discontinuation of antihypertensive treatment by two-drug combination as first step. Evidence from daily life practice. J Hypertens. 2010;28(7):1584-90.

34. Degli Esposti L, Saragoni S, Buda S, Degli Esposti E. Drug adherence to olmesartan/amlodipine fixed combination in an Italian clinical practice setting. Clinicoecon Outcomes Res. 2014;6:209-16. Available at: https://www. dovepress.com/drug-adherence-to-olmesartanamlodipine-fixed-combination-in-an-italian-peer-reviewed-article-CEOR. Accessed December 1, 2015.
35. Perseguer-Torregrosa Z, Orozco-Beltrán D, Gil-Guillen V, et al. Magnitude of pharmacological nonadherence in hypertensive patients taking antihypertensive medication from a community pharmacy in Spain. J Manag Care Spec Pharm. 2014;20(12):1217-25. Available at: http://www.amcp.org/ WorkArea/DownloadAsset.aspx?id=18842.

36. Italian Ministry of Health. Ministerial Decree 22 July 1996, N. 32731. Prestazioni Di Assistenza Specialistica Ambulatoriale Erogabili Nell'ambito Del Servizio Sanitario Nazionale E Relative Tariffe. Rome, Italy: Italian Ministry of Health; 1996.

37. Lawrenson R, Williams T, Farmer R. Clinical information for research; the use of general practice databases. J Public Health Med. 1999;21(3):299304. Available at: http://jpubhealth.oxfordjournals.org/content/21/3/299. long. Accessed December 1, 2015.

38. Cricelli C, Mazzaglia G, Samani F, et al. Prevalence estimates for chronic diseases in Italy: exploring the differences between self-report and primary care databases. J Public Health Med. 2003;25(3):254-57. Available at: http:// jpubhealth.oxfordjournals.org/content/25/3/254.long. Accessed December $1,2015$.

39. Mazzaglia G, Sessa E, Samani F, Cricelli C, Fabiani L. Use of computerized general practice database for epidemiological studies in Italy: a comparative study with the official national statistics. J Epidemiol Commun Health. 2004;58(Suppl 1):A133.

40. Gruppo di lavoro dell'Osservatorio Nazionale sull'Impiego dei Medicinali. L'uso Dei Farmaci in Italia. Rapporto Nazionale Anno 2012. Rome: Agenzia Italiana del Farmaco; 2013. Available at: http://www.agenziafarmaco.gov.it/sites/default/files/Rapporto_OsMed_2012.pdf. Accessed December $18,2015$.

41. Andrade SE, Kahler KH, Frech F, Chan KA. Methods for evaluation of medication adherence and persistence using automated databases. Pharmacoepidemiol Drug Saf. 2006;15(8):565-74; discussion 575-77.

42. Rasmussen JN, Chong A, Alter DA. Relationship between adherence to evidence-based pharmacotherapy and long-term mortality after acute myocardial infarction. JAMA. 2007;297(2):177-86.

43. Cameron A, Miller D. A practitioner's guide to cluster-robust inference. J Hum Resour. 2015;50(2):317-72.

44. Bramlage P, Ketelhut R, Fronk E-M, et al. Clinical impact of patient adherence to a fixed-dose combination of olmesartan, amlodipine and hydrochlorothiazide. Clin Drug Investig. 2014;34(6):403-11.

45. Gavrielov-Yusim N, Friger M. Use of administrative medical databases in population-based research. J Epidemiol Community Health. 2014;68(3):283-87.

46. Koschack J, Marx G, Schnakenberg J, Kochen MM, Himmel W.

Comparison of two self-rating instruments for medication adherence assessment in hypertension revealed insufficient psychometric properties. J Clin Epidemiol. 2010;63:299-306.

47. Thom S, Poulter N, Field J, et al.; UMPIRE Collaborative Group. Effects of a fixed-dose combination strategy on adherence and risk factors in patients with or at high risk of CVD: the UMPIRE randomized clinical trial. JAMA. 2013;310(9):918-29.

48. Gupta AK, Arshad S, Poulter NR. Compliance, safety, and effectiveness of fixed-dose combinations of antihypertensive agents: a meta-analysis. Hypertension. 2010;55(2):399-407.

49. Osterberg L, Blaschke T. Adherence to medication. N Engl J Med. 2005;353(5):487-97.

50. Alacqua M, Trifirò G, Cavagna L, et al. Prescribing pattern of drugs in the treatment of osteoarthritis in Italian general practice: the effect of rofecoxib withdrawal. Arthritis Rheum. 2008;59(4):568-74.

51. Oteri A, Trifirò G, Gagliostro MS, et al. Prescribing pattern of anti-epileptic drugs in an Italian setting of elderly outpatients: a population-based study during 2004-07. Br J Clin Pharmacol. 2010;70(4):514-22.

52. Ferrajolo C, Arcoraci V, Sullo MG, et al. Pattern of statin use in southern Italian primary care: can prescription databases be used for monitoring long-term adherence to the treatment? PLoS ONE. 2014;9(7):e102146. 